\title{
Livestock grazing but not exotic grass invasion are associated with a seasonal reduction in wild bee biodiversity and functional variation in shortgrass prairie
}

\author{
Khum Thapa-Magar ${ }^{1}$, Thomas Davis ${ }^{1}$, and Boris Kondratieff ${ }^{1}$ \\ ${ }^{1}$ Colorado State University
}

June 17, 2020

\begin{abstract}
1. Livestock grazing and non-native plant species affect rangeland habitats globally. These factors may have important effects on ecosystem services including pollination, yet, interactions between pollinators, grazing, and invasive plants are poorly understood. To address this, we tested the hypothesis that cattle grazing and site colonization by cheatgrass (Bromus tectorum) impact bee foraging and nesting habitats and the biodiversity of wild bee communities in a shortgrass prairie system. 2 . Bee nesting habitats (litter and wood cover) were marginally improved in non-grazed sites, though foraging habitat (floral cover and richness) did not differ among grazed, non-grazed, or cheatgrass colonized sites. However, floral cover was a good predictor of bee abundance and functional dispersion. 3. Mean bee abundance, richness, $\alpha$-diversity and functional diversity were significantly lower in cattle-grazed habitats than in cheatgrass-colonized or non-grazed habitats. Differences in bee diversity among habitats were pronounced early in the growing season (May) but by late-season (August) these differences eroded. Fourth-corner analysis revealed that sites with high floral cover tended to support large, social, polylectic bees; sites with high grass cover tended to support oligolectic solitary bees. Both cattle-grazed and cheatgrass-colonized sites were associated with lower abundances of above-ground nesting bees but higher abundance of below-ground nesters. 4. Synthesis and applications. Cheatgrass-invaded sites do not appear to be associated with reduced bee biodiversity or abundance, but cattle grazing was negatively associated with bee abundances and altered species composition. Although floral cover is an important predictor of bee assemblages, this was not impacted by grazing and our suggests that cattle likely impact bee communities through effects other than those mediated by forbs, including soil disturbance or nest destruction. Efforts aimed at pollinator conservation in prairie habitats should focus on managing cattle impacts early in the growing season to benefit sensitive bee species.
\end{abstract}

\section{Hosted file}

Thapa-Magar_JAE_2020_JUN16.pdf available at https://authorea.com/users/334287/articles/ 460291-livestock-grazing-but-not-exotic-grass-invasion-are-associated-with-a-seasonalreduction-in-wild-bee-biodiversity-and-functional-variation-in-shortgrass-prairie 